\title{
Impacts of Thermal Inertia Factor on Adiabatic Decomposition of 40\% Mass Content DCP in Ethyl Benzene
}

\author{
Xiaojuan Wu, ${ }^{1,2}$ Liping Chen $\left(\mathbb{D},{ }^{1}\right.$ Guoning Rao ${ }^{D},{ }^{1}$ Wanghua Chen, ${ }^{1}$ and Ruili Yin ${ }^{1}$ \\ ${ }^{1}$ Department of Safety Engineering, School of Chemical Engineering, Nanjing University of Science and Technology, \\ Nanjing 210094, China \\ ${ }^{2}$ Zhenjiang Key Laboratory of Functional Chemistry, Institute of Medicine \& Chemical Engineering, Zhenjiang College, \\ Zhenjiang 212028, China \\ Correspondence should be addressed to Liping Chen; clp2005@hotmail.com
}

Received 10 August 2019; Revised 6 February 2020; Accepted 12 February 2020; Published 13 May 2020

Academic Editor: Claudia Crestini

Copyright (c) 2020 Xiaojuan Wu et al. This is an open access article distributed under the Creative Commons Attribution License, which permits unrestricted use, distribution, and reproduction in any medium, provided the original work is properly cited.

\begin{abstract}
To reduce the fire and explosion accident of dicumyl peroxide (DCP) in experiment and production, the thermal hazards of DCP and $40 \%$ mass content DCP in ethyl benzene ( $40 \%$ DCP) have been studied by the differential scanning calorimeter (DSC) and the accelerating rate calorimeter (ARC) in this paper. DSC experiment showed that ethyl benzene has no effect on the characteristic parameters of thermal decomposition of DCP, such as the temperature of the exothermic peak $\left(T_{\text {peak }}\right)$ and the decomposition energy $\left(E_{\mathrm{a}}\right)$, and the thermal decomposition reaction of $40 \%$ DCP followed the one-step reaction principle. ARC experiment showed that with the increase of inertia factor $(\Phi)$, the measured initial decomposition temperature $\left(T_{\text {on }}\right)$ would be higher and the caculated $E_{\mathrm{a}}$ and pre-exponential factor $(A)$ would be greater. It was also proved that after modification of $\Phi, T_{\mathrm{D} 24}$ was relatively consistent near $T_{\text {on }}$, but different at higher temperatures. Fisher's correction method was used to verify the necessity of consistency between experimental conditions and prediction conditions.
\end{abstract}

\section{Introduction}

With fast development of industries and wide usage of organic peroxides, the hazard assessment of organic peroxides has become more and more important in many countries. As a kind of common organic peroxides, dicumyl peroxide (DCP) has been widely employed as a vulcanizing agent of rubber and a crosslinking agent of plastic in the chemical industry. Because of the thermal sensitivity and high antipyretic effect of DCP, great damages would be brought into the production process, workers, and environment once the reaction runaway occurs $[1,2]$.

Thermal analyses have been carried out on organic peroxides by different thermal analysis apparatuses. Ding [3] has investigated the thermal decomposition of DCP by the thermogravimetry-differential thermogravimetry (TGDTG) method. One endothermic peak and one exothermic peak were found in the decomposition process, and the apparent activation energy was calculated. Jiang [4] has studied the influence on the heating rates of DCP by C80. The advanced kinetics and technology solutions (AKTS) method has been used to calculate the thermodynamic parameters. Guo [5] has used an accelerating rate calorimeter (ARC) to determine the adiabatic decomposition rule of DCP. "Townsend-Tou" method has been used in the correction of the experiment data.

Although the sample is small, the maximum self-heating rate can exceed the maximum tracking rate of ARC for the large decomposition heat of DCP. It will result in some errors in the experiment [6]. In order to reduce the decomposition heat of DCP, ethyl benzene is chosen as the solvent for its stability within the test scope in this paper. Thermodynamic and kinetic parameters of pure DCP and $40 \%$ mass content DCP in ethyl benzene can be obtained by a differential scanning calorimeter (DSC) and ARC. Based on these thermal data, safety studies can be done to distinguish the dangers caused by the two material systems. Furthermore, with "Fisher's" method, the best experiment condition of ARC will be discussed. 


\section{Materials and Methods}

DCP of $99.5 \%$ mass content was purchased from Aladdin. It is in the solid state at room temperature. Ethyl benzene of $98.5 \%$ mass content is bought from Sinopharm Chemical Reagent Co., Ltd. It is in the liquid state at room temperature.

$40 \%$ mass content DCP in ethyl benzene (40\% DCP) was prepared by assuming both DCP and ethyl benzene were at $100 \%$ purity. The configured solution was placed in a refrigerator. It is in the liquid state, and the density is $1.044 \mathrm{~g} \cdot \mathrm{cm}^{-3}$ at room temperature.

The heat capacities of DCP and $40 \%$ DCP at $90^{\circ} \mathrm{C}$ were 1.94 and $1.95 \mathrm{~J} \cdot \mathrm{g}^{-1} \cdot \mathrm{K}^{-1}$, respectively, which were obtained from uRC (manufactured by THT).

2.1. DSC Experiments. The DSC used in this paper was manufactured by Mettler Toledo (DSC-1). Stainless steel high-pressure crucibles $(15 \mathrm{MPa})$ were employed in tests, with extra pure nitrogen purging $\left(30 \mathrm{~mL} \cdot \mathrm{min}^{-1}\right)$. Samples were tested at a heating rate of $2,4,8$, and $1 \mathrm{~K} \cdot \mathrm{min}^{-1}$ for rapid screening. The temperature range of all measurements was from 25 to $250^{\circ} \mathrm{C}$.

2.2. ARC Experiments. ARC supplied by Thermal Hazard Technology Company was performed in the heat-waitsearch mode. The experimental procedure was sealed. The temperature step was $5^{\circ} \mathrm{C}$, the wait time was 10 minutes, and the slop sensitivity was $0.02^{\circ} \mathrm{C} \cdot \mathrm{min}^{-1}$. The trackable heating rate was up to $15^{\circ} \mathrm{C} \cdot \mathrm{min}^{-1}$ (full power). Sample bomb was made of titanium with a thick wall of $0.5 \mathrm{~mm}$, and the heat capacity and density are $0.53 \mathrm{~J} \cdot \mathrm{g}^{-1} \cdot \mathrm{K}^{-1}$ and $4.53 \mathrm{~g} \cdot \mathrm{cm}^{-3}$, respectively. The ARC test temperature range is from the room temperature to $450^{\circ} \mathrm{C}$.

The mass of each sample is listed in Tables 1 and 2.

\section{Results and Discussion}

\subsection{Analysis of DSC Measurement}

3.1.1. Comparison of \#1 and \#2 with the DSC Test. The DSC results of samples $\# 1$ and $\# 2$ at $8 \mathrm{~K} \cdot \mathrm{min}^{-1}$ are shown in Figure 1 and Table 3.

According to Figure 1, it is found that thermal decomposition of DCP contains one endothermic peak at $43.12^{\circ} \mathrm{C}$ and one exothermic peak at $177.40^{\circ} \mathrm{C}$. Since ethyl benzene does not decompose in the test scope, DCP is dissolved into ethyl benzene and decomposed without the influence of phase transition, and this is why there is only one exothermic peak for $40 \%$ DCP. The onset exothermic temperature of DCP and $40 \%$ DCP is approaching $115^{\circ} \mathrm{C}$. There is a big difference of decomposition heat $(\Delta H)$ between DCP and 40\% DCP in Table 3, and they are 886.58 and $362.88 \mathrm{~J} \cdot \mathrm{g}^{-1}$, respectively. However, when we divide 649.56 (the total heat of $40 \%$ DCP) by 0.792 (mass of DCP in sample $\# 2$ ), the value is $907.22 \mathrm{~J} \cdot \mathrm{g}^{-1}$, which is close to the $\Delta H$ of sample \#1. So, it can be concluded that ethyl benzene has little impact on the decomposition of DCP.
3.2. Test Results of Sample \# 2 under Different Heating Rates with the DSC Test. A typical run for sample \#2 at different heating rates is shown in Figure 2. The characteristic parameters are given in Table 4.

The Friedman isoconversional method was employed to calculate the kinetics in this paper. As a "model-free" dynamic analysis method, it does not need to use concrete mechanism function, and the result has high precision and wide application [7]. We get a Friedman analysis diagram which shows the relationship between $E_{\mathrm{a}}$ and $\alpha$, as in Figure 3 and Table 5.

As given in Table 5, between $\alpha=0.2$ and $0.9, E_{\mathrm{a}}$ is between 110.60 and $98.14 \mathrm{~kJ} \cdot \mathrm{mol}^{-1}$ and the variation range is nearly $10 \%$, indicating that it follows a reaction mechanism and can be expressed by the same mechanism function for $40 \%$ DCP.

3.3. Analysis of ARC Measurement. Seven experiments with different ${ }_{\Phi}$ are carried out according to the above conditions. The ARC curves of temperature-time $(T-t)$ and pressuretime $(P-t)$ of sample \#2 are shown in Figures 4 and 5, and all measured data are listed in Table 6.

As shown in Figure 4, the ARC curve of the first test is different from others, and the exothermal reaction is divided into two parts. Table 6 shows that the maximum self-heating rate $\left((\mathrm{d} T / \mathrm{d} t)_{\max , \mathrm{m}}\right)$, the measured adiabatic temperature rise $\left(\Delta \mathrm{T}_{\mathrm{ad}, \mathrm{m}}\right)$, and the decomposition heat $\left(H_{\mathrm{m}}\right)$ of the first test are much smaller than other tests. The small sample mass results in high $\Phi$ of the first test, and it makes part of the (dT/ $\mathrm{d} t)_{\mathrm{m}}$ less than the detection sensitivity $0.02^{\circ} \mathrm{C} \cdot \mathrm{min}^{-1}$ and part of the decomposition heat is missed. Obviously, too large $\Phi$ can change the temperature curve entirely and result in the distortion of the tested results.

As shown in Table $6, T_{\text {on,m }}$ is rising with the increase of $\Phi$. The reason is that the small amount of the sample needs a higher temperature to make the $(\mathrm{d} T / \mathrm{d} t)_{\mathrm{m}}$ of the sample and the bomb system reach the ARC detection sensitivity $\left(0.02^{\circ} \mathrm{C} \cdot \mathrm{min}^{-1}\right)$. It is also shown that $\Delta \mathrm{TM}$ and $(\mathrm{d} T / \mathrm{d} t)_{\max , \mathrm{m}}$ decrease with the increase in $\Phi$. In addition, since the material and energy balance of the sample and the bomb system were complicated, the $(\mathrm{d} T / \mathrm{d} t)_{\max , \mathrm{m}}$ with $\Phi$ was less linear.

3.4. Kinetic Calculation. The heat released by the sample in the ARC test not only heats the sample itself, but also raises the temperature of the bomb. The smaller the sample mass, the higher proportion of heat will be used for heating the bomb and the corresponding temperature parameters (such as temperature curves and heating rate curves) will be affected too. So, it is very important to introduce the thermal inertia factor $\Phi$, which can be estimated by the following equation:

$$
\Phi=\frac{m_{s} C_{s}+m_{b} C_{b}}{m_{s} C_{s}} .
$$

The Townsend-Tou method [8-10] and the Fisher method [11-13] have been widely used. Literature [3] shows that thermal decomposition of DCP is an $n$ th-order reaction, 
TABle 1: Mass in DSC tests.

\begin{tabular}{|c|c|c|c|c|}
\hline \multirow{2}{*}{ Samples } & \multicolumn{2}{|c|}{ Essential components (\%) } & \multirow{2}{*}{ Sample mass (mg) } & \multirow{2}{*}{ Heating rate $\left(\mathrm{K} \cdot \mathrm{min}^{-1}\right)$} \\
\hline & DCP & Ethyl benzene & & \\
\hline$\# 1$ & 100 & 0 & 1.26 & 8 \\
\hline \multirow{4}{*}{$\# 2$} & 40 & 60 & 1.98 & 2 \\
\hline & 40 & 60 & 1.98 & 4 \\
\hline & 40 & 60 & 1.98 & 8 \\
\hline & 40 & 60 & 1.98 & 10 \\
\hline
\end{tabular}

TABle 2: Mass in ARC tests.

\begin{tabular}{lcccccccrr}
\hline \multirow{2}{*}{ Samples } & \multicolumn{2}{c}{ Essential components (\%) } & \multicolumn{4}{c}{ Mass (mg) } \\
& DCP & Ethyl benzene & No. 1 & No. 2 & No. 3 & No. 4 & No. 5 & No. 6 & No. 7 \\
\hline$\# 2$ & 40 & 60 & 0.510 & 0.593 & 1.005 & 1.501 & 2.316 & 2.551 & 4.283 \\
\hline
\end{tabular}

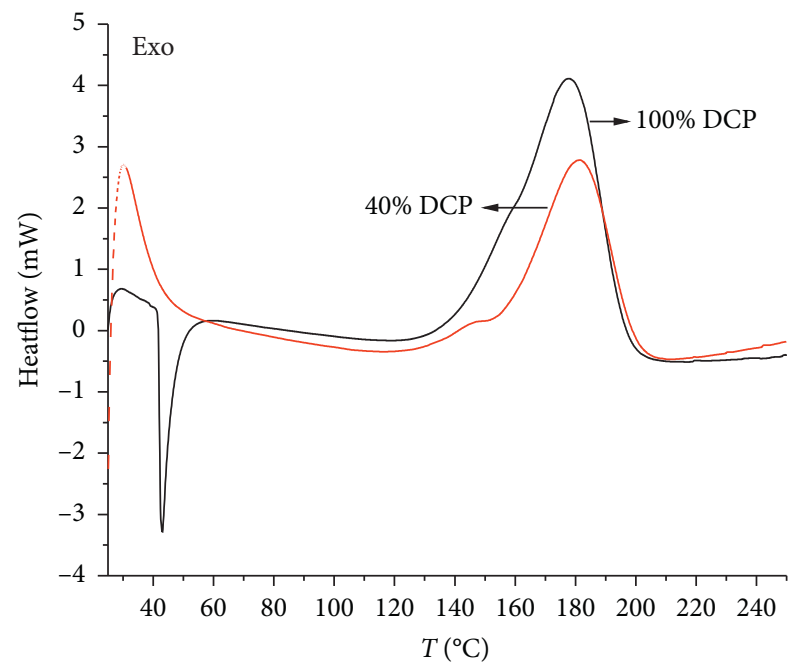

FIgURE 1: DSC curve of samples $\# 1$ and $\# 2$ at $8 \mathrm{~K} \cdot \mathrm{min}^{-1}$.

TABLE 3: DSC results of samples \#1 and $\# 2$ at $8 \mathrm{~K} \cdot \mathrm{min}^{-1}$.

\begin{tabular}{lccccc}
\hline Samples & $\begin{array}{c}\text { Mass } \\
(\mathrm{mg})\end{array}$ & $\begin{array}{c}T_{\text {onset }} \text { of } \\
\text { exo }\end{array}$ & $\begin{array}{c}T_{\text {peak }} \text { of } \\
\text { exo }\end{array}$ & $\begin{array}{c}\Delta H^{\mathrm{a}} \\
\left(\mathrm{J} \cdot \mathrm{g}^{-1}\right)\end{array}$ & $\begin{array}{c}\Delta H_{b}^{d} \\
\left(\mathrm{~J} \cdot \mathrm{g}^{-1}\right)\end{array}$ \\
\hline$\# 1$ & 1.26 & 115.7 & 177.4 & 886.58 & 886.58 \\
$\# 2$ & 1.98 & 114.7 & 181 & 362.88 & 907.22 \\
\hline
\end{tabular}

${ }^{\mathrm{a}}$ Dividing total heat by total mass of the sample, $\Delta H$. ${ }^{\mathrm{b}}$ Dividing total heat by total mass of DCP, $\Delta H_{\mathrm{d}}$.

and the Fisher method is adopted to modify the ARC data in this paper.

The corrected equations for the Fisher method are listed as follows:

$$
\begin{aligned}
\frac{1}{T_{\text {on, a }}} & =\frac{1}{T_{\text {on }, \mathrm{m}}}+\frac{R}{E_{\mathrm{a}}} \ln \Phi, \\
T_{\mathrm{ad}, \mathrm{a}} & =T_{\text {on }, \mathrm{a}}+\Phi\left(T_{m}-T_{\text {on, } \mathrm{m}}\right), \\
\left(\frac{\mathrm{d} T}{\mathrm{~d} t}\right)_{\mathrm{ad}, \mathrm{a}} & =\Phi\left(\frac{\mathrm{d} T}{\mathrm{~d} t}\right)_{\mathrm{ad}, \mathrm{m}} \exp \left[\frac{E_{\mathrm{a}}}{R}\left(\frac{1}{T_{\text {on, } \mathrm{a}}}-\frac{1}{T_{\text {ad,a }}}\right)\right],
\end{aligned}
$$

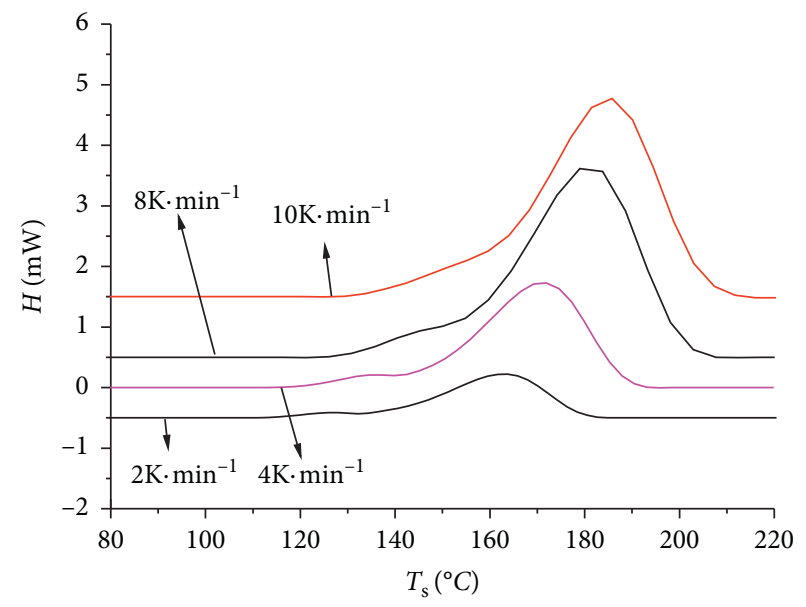

Figure 2: Heatflow of sample \#2 under different heating rates.

TABLE 4: Results for 40\% DCP with the DSC test.

\begin{tabular}{lcccc}
\hline \multicolumn{5}{c}{$40 \%$ DCP } \\
\hline$\beta / \mathrm{K} \cdot \mathrm{min}^{-1}$ & 2 & 4 & 8 & 10 \\
$T_{0}\left({ }^{\circ} \mathrm{C}\right)$ & 138.36 & 144.72 & 153.69 & 156.96 \\
$T_{\mathrm{p}}\left({ }^{\circ} \mathrm{C}\right)$ & 163.75 & 171.90 & 178.99 & 185.79 \\
$\mathrm{Q} / \mathrm{J} \cdot \mathrm{g}^{-1}$ & 293.80 & 365.81 & 362.94 & 302.93 \\
\hline
\end{tabular}

where $R$ is the gas constant; $E_{\mathrm{a}}$ is the apparent activation energy, $\mathrm{kJ} \cdot \mathrm{mol}^{-1} ; T_{\mathrm{on}, \mathrm{m}}$ is the corrected onset temperature by the Fisher method, ${ }^{\circ} \mathrm{C} ; T_{\mathrm{ad}, \mathrm{a}}$ is the corrected temperature by the Fisher method, ${ }^{\circ} \mathrm{C} ;(\mathrm{dT} / \mathrm{d} t)_{\mathrm{ad}, \mathrm{a}}$ is the corrected selfheating rate by the Fisher method, $\mathrm{K} \cdot \mathrm{min}^{-1}$; and $(\mathrm{d} T / \mathrm{d} t)_{\mathrm{ad}, \mathrm{m}}$ is the measured self-heating rate, $\mathrm{K} \cdot \mathrm{min}^{-1}$.

The corrected results are listed in Table 7.

Kinetic parameters are important for thermal hazard prediction. For the decomposition reaction in the adiabatic system, the relationship between temperature and the selfheating rate is [14]

$$
\left(\frac{\mathrm{d} T}{\mathrm{~d} t}\right)_{\mathrm{a}}=A\left(\frac{T_{\mathrm{f}, \mathrm{a}}-T_{\mathrm{ad}, \mathrm{a}}}{\Delta T_{\mathrm{ad}, \mathrm{a}}}\right)^{n} \Delta T_{\mathrm{ad}, \mathrm{a}} c_{0}^{n-1} \exp \left(-\frac{E_{\mathrm{a}}}{R T_{\mathrm{ad}, \mathrm{a}}}\right),
$$




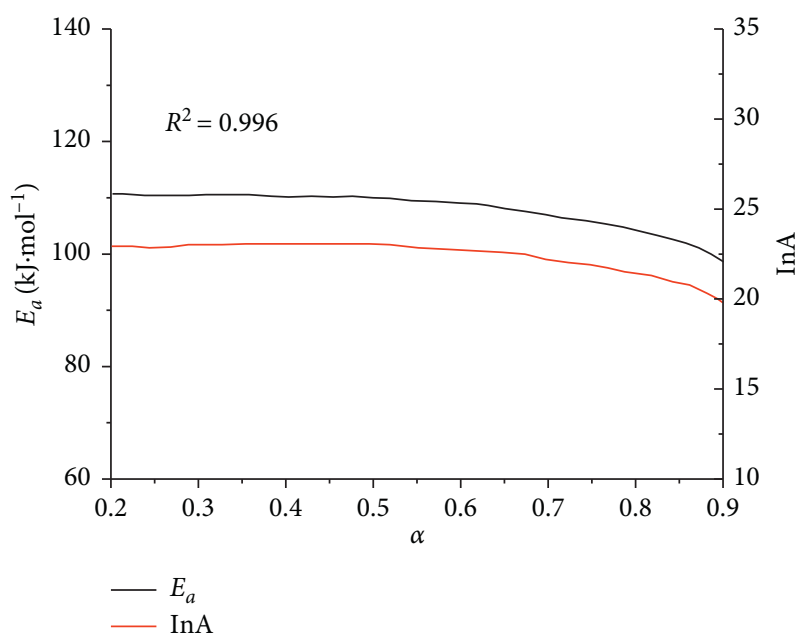

Figure 3: $E_{a}(\alpha)$ and $\ln A(\alpha)$ vs $\alpha$ of sample \#2.

Table 5: $\ln A$ and $E_{\mathrm{a}}$ values of $40 \%$ DCP obtained by the Friedman method.

\begin{tabular}{cccccccccc}
\hline & $\alpha$ & 0.2 & 0.3 & 0.4 & 0.5 & 0.6 & 0.7 & 0.8 & 0.9 \\
\hline \multirow{2}{*}{$40 \%$ DCP } & $E_{\mathrm{a}} / \mathrm{kJ} \cdot \mathrm{mol}^{-1}$ & 110.60 & 110.42 & 110.08 & 109.95 & 108.90 & 106.91 & 104.16 & 98.14 \\
& $\ln \left(\mathrm{A} / \mathrm{s}^{-1}\right)$ & 22.93 & 23.00 & 22.98 & 22.99 & 22.72 & 22.19 & 21.42 & 19.75 \\
\hline
\end{tabular}

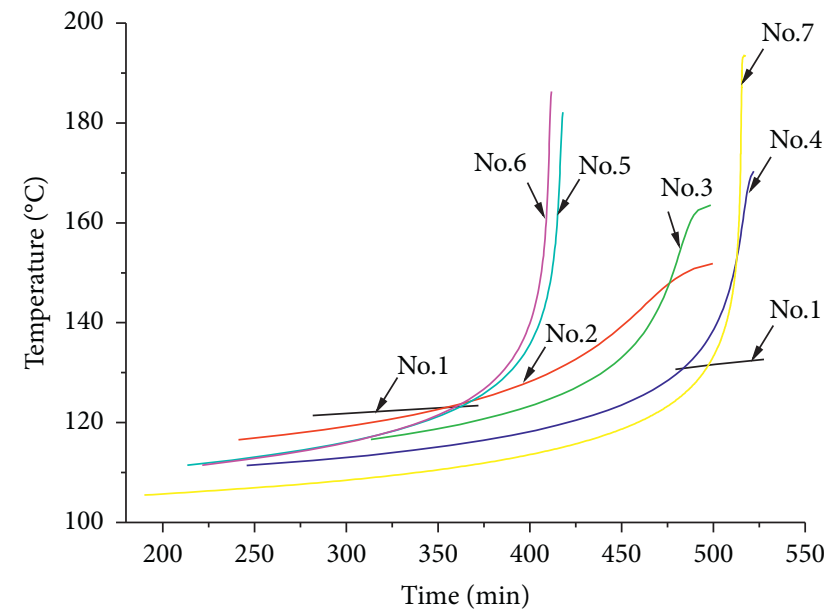

FIgURE 4: $T$ - $t$ of exothermic section for sample \#2.

where $T_{\mathrm{f}, \mathrm{a}}$ is the corrected final temperature of decomposition, ${ }^{\circ} \mathrm{C} ; A$ is the pre-exponential factor, $\min ^{-1} ; n$ is the reaction order; and $c_{0}$ is the initial concentration of sample, $\mathrm{mol} \cdot \mathrm{L}^{-1}$.

Suppose

$$
\begin{aligned}
k^{*} & =k c_{0}^{n-1}=c_{0}^{n-1} A \exp \left(-\frac{E_{\mathrm{a}}}{R T_{\mathrm{a}}}\right) \\
& =\left(\frac{\mathrm{d} T}{\mathrm{~d} t}\right)_{\mathrm{a}}\left(\frac{\Delta T_{\mathrm{ad}, \mathrm{a}}}{T_{\mathrm{f}, \mathrm{a}}-T_{\mathrm{ad}, \mathrm{a}}}\right)^{n} \Delta T_{\mathrm{ad}, \mathrm{a}}^{-1}
\end{aligned}
$$

where $k$ is the rate constant.

Logarithmic form of equation (4)is

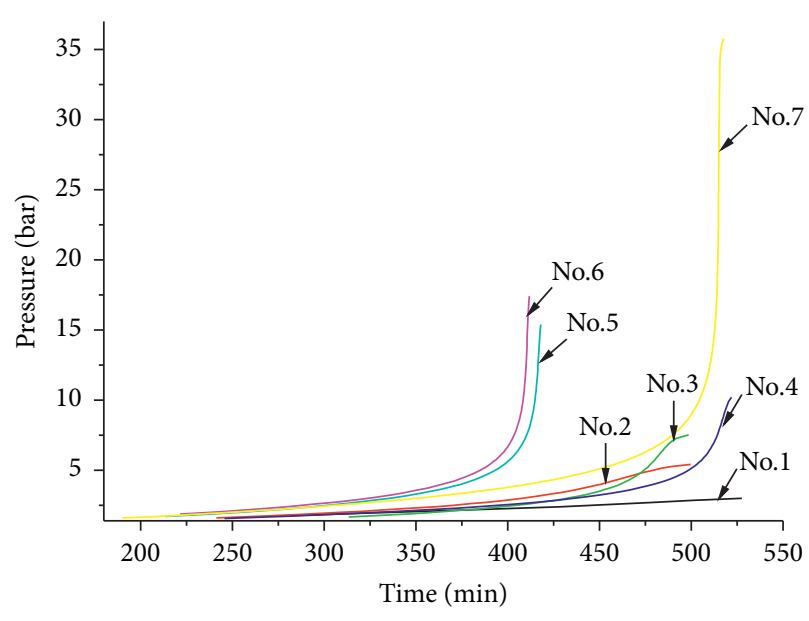

Figure 5: $P$ - $t$ of exothermic section for sample $\# 2$.

$$
\ln k^{*}=\ln \left(A c_{0}{ }^{n-1}\right)-\frac{E_{\mathrm{a}}}{R} \frac{1}{T_{\mathrm{ad}, \mathrm{a}}} .
$$

The reaction order which can make the plot of $\ln \left(k^{*}\right)$ vs. $1 / \mathrm{T}_{\mathrm{ad}, \mathrm{a}}$ to be a straight line is analysed correctly. Then, $E_{\mathrm{a}}$ and $A$ can be calculated from the slope and the intercept.

The kinetic analysis is not applied to the first test for its self-heating rate is discontinuous. For other samples, the reaction order $n=1$ is assumed and substituted into equation (4), and then $\ln \left(k^{*}\right)$ is plotted against $1 / T_{\text {ad,a. }}$. Linear fitting of $\ln \left(k^{*}\right)$ and $1 / T_{\mathrm{ad}, \mathrm{a}}$ is done, and the fitting results and the values of $E_{\mathrm{a}}$ and $A$ are shown in Table 8.

The high correlation coefficient indicates that the linear fitting results are reliable when $n=1$. It means that the DCP decomposition is a very typical $n$-order reaction, and the 
TABLE 6: Measured adiabatic test results of sample \#2 with different $\Phi$ values.

\begin{tabular}{lcccccc}
\hline No. & $\mathrm{T}_{\text {on,m }}\left({ }^{\circ} \mathrm{C}\right)$ & $\Delta \mathrm{T}_{\mathrm{ad}, \mathrm{m}}\left({ }^{\circ} \mathrm{C}\right)$ & $(\mathrm{d} T / \mathrm{d} t)_{\max , \mathrm{m}}$ & $\mathrm{T}_{\text {max,m }}\left({ }^{\circ} \mathrm{C}\right)$ & $\mathrm{H}_{\mathrm{m}}\left(\mathrm{J} \cdot \mathrm{g}^{-1}\right)$ & $\mathrm{P}_{\text {end,m }}(\mathrm{bar})$ \\
\hline 1 & 120.43 & First part: 4.00 & 0.024 & 131.67 & 49.34 \\
2 & 115.54 & Second part: 2.01 & 0.36 & 143.74 & 266.00 \\
3 & 115.60 & 36.28 & 1.21 & 155.35 & 245.86 \\
4 & 110.42 & 47.94 & 2.65 & 162.94 & 244.08 \\
5 & 110.49 & 79.89 & 10.38 & 166.51 & 238.92 \\
6 & 110.50 & 75.81 & 12.97 & 175.86 & 242.44 \\
7 & 105.49 & 87.88 & 166.52 & 175.56 & 238.00 \\
\hline
\end{tabular}

$\mathrm{T}_{\mathrm{on}, \mathrm{m}}$, measured onset decomposition temperature, ${ }^{\circ} \mathrm{C} . \Delta \mathrm{T}_{\mathrm{ad}, \mathrm{m}}$, measured adiabatic temperature rise, ${ }^{\circ} \mathrm{C} .(\mathrm{d} T / \mathrm{d} t)_{\max , \mathrm{m}}$, measured maximum self-heating rate, $\mathrm{K} \cdot \mathrm{min}^{-1} \cdot \mathrm{T}_{\max , \mathrm{m}}$, measured temperature at maximum rate, ${ }^{\circ} \mathrm{C} . \mathrm{P}_{\text {end,m }}$, measured final pressure of decomposition, bar.

Table 7: Adiabatic test results of sample \#2 corrected by the Fisher method.

\begin{tabular}{lcccccc}
\hline No. & 2 & 3 & 4 & 5 & 6 & 7 \\
\hline$\Phi$ & 3.76 & 2.63 & 2.09 & 1.71 & 1.39 \\
$\mathrm{~T}_{\text {on,a }}\left({ }^{\circ} \mathrm{C}\right)$ & 106.86 & 108.84 & 105.45 & 106.79 & 1.64 & 107.03 \\
$\Delta \mathrm{T}_{\text {ad,a }}\left({ }^{\circ} \mathrm{C}\right)$ & 136.41 & 126.08 & 125.17 & 122.52 & 124.33 \\
$(\mathrm{~d} T / \mathrm{d} t)_{\text {max }, \mathrm{a}}$ & 6964.1 & 1491.9 & 1184.4 & 928.8 & 913.3 & 122.15 \\
\hline
\end{tabular}

$\mathrm{T}_{\mathrm{on}, \mathrm{a}}$, corrected onset decomposition temperature, ${ }^{\circ} \mathrm{C} . \Delta \mathrm{T}_{\mathrm{ad}, \mathrm{a}}$, corrected adiabatic temperature rise, ${ }^{\circ} \mathrm{C} .(\mathrm{d} T / \mathrm{d} t)_{\max , \mathrm{a}}$, corrected maximum self-heating rate, $\mathrm{K} \cdot \mathrm{min}^{-1}$.

TABLE 8: The linear fitting results.

\begin{tabular}{lcccccc}
\hline No. & 2 & 3 & 4 & 5 & 6 \\
\hline$\Phi$ & 3.76 & 2.63 & 2.09 & 1.71 & 1.64 & 1 \\
$n$ & 1 & 1 & 1 & 1 & 1 & 1 \\
$E_{\mathrm{a}}\left(\mathrm{kJ} \cdot \mathrm{mol}^{-1}\right)$ & 187.30 & 176.51 & 178.92 & 175.70 & 172.76 \\
$A\left(\mathrm{~min}^{-1}\right)$ & $1.38 \times 10^{22}$ & $5.00 \times 10^{20}$ & $1.01 \times 10^{21}$ & $3.84 \times 10^{20}$ & $1.58 \times 10^{20}$ & $5.00 \times 10^{19}$ \\
$R^{2}$ & 0.9964 & 0.9992 & 0.9981 & 0.9969 & 0.9982 & 0.9968 \\
\hline$R^{2}$ linear fitting correlation coefficient. & & & &
\end{tabular}

Fisher method which is selected for correction before is appropriate.

In addition, a good linear regression of $\ln A$ vs. $E_{\mathrm{a}}$ is found with different $\Phi$, showing a typical kinetic compensation effect [15], as shown in Figure 6. This means that the kinetic compensation effect exists only if the reaction mechanism is the same or similar [16].

Comparing DSC and ARC experiments, we can find that the calculated $E_{\mathrm{a}}$ in ARC is generally higher than that in DSC and higher with the increase in $\Phi$. It is mainly because these calculated kinetic parameters obtained by ARC data depend on the adiabatic temperature rise rate of equation (3).With the influence of the big $\Phi$ values, the measured adiabatic temperature rise curve of the sample is not the decomposition curve of itself, and it is the curve which is formed after the sample ball "passivation." So, this analysis of kinetic parameters is not incidental to the sample decomposition, but to the decomposition of composite samples, sample ball, heat transfer, and heat transfer information such as the comprehensive parameter.

3.5. Effect of $\Phi$ on $T_{D 24}$. The corresponding initial temperature when the time to maximum rate under adiabatic condition $\left(T M R_{\mathrm{ad}}\right)$ equals 24 hours $\left(T_{\mathrm{D} 24}\right)$ is an important

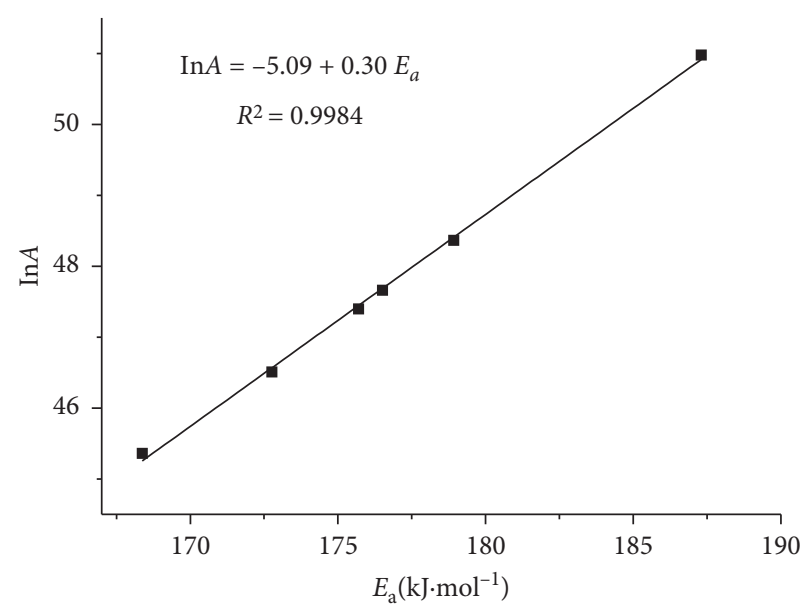

Figure 6: $\ln A$ vs $\mathrm{E}_{\mathrm{a}}$ with different values of $\Phi$.

parameter to evaluate the risk of samples. In order to obtain the effects of different $\Phi$ on the measured $T_{\mathrm{D} 24, \mathrm{~m}}$ and the modified $T_{\mathrm{D} 24}$, the experimental data before and after the correction are analysed in this paper. It can be seen from Table 6 that $(\mathrm{d} T / \mathrm{d} t)_{\text {max,m }}$ measured in No. 1 and No. 2 is less than 1 , while in No. 7 is $166.52^{\circ} \mathrm{C} \cdot \mathrm{min}^{-1}$, indicating an 
unsatisfactory adiabatic environment. Therefore, the data of $40 \%$ DCP solution in No. 1, No. 2, and No. 7 are not analysed in this part and only comparing the data of the other four groups is done.

The measured $T M R_{\mathrm{ad}}$ can be obtained by the following method:

$$
\begin{aligned}
T M R_{\mathrm{ad}, \mathrm{m}}= & t_{m}-t=\int_{t}^{t_{m}} \mathrm{~d} t=\int_{T}^{T_{m}} \\
& \frac{\mathrm{d} T}{A \exp ^{-E_{a} / \mathrm{RT}}\left(\left(T_{f}-T\right) / \Delta T_{\mathrm{ad}}\right)^{n} \Delta T_{\mathrm{ad}} C_{0}^{n-1}},
\end{aligned}
$$

where $T M R_{\mathrm{ad}, \mathrm{m}}$ is the measured arrival time of the maximum reaction rate, $\mathrm{min} ; T_{\mathrm{m}}$ is the temperature corresponding to the maximum temperature rise rate, ${ }^{\circ} \mathrm{C} ; t_{\mathrm{m}}$ is the time corresponding to $T_{\mathrm{m}}$, min; $T_{\mathrm{f}}$ is the exothermic termination temperature, ${ }^{\circ} \mathrm{C}$; $T$ is the adiabatic test temperature, ${ }^{\circ} \mathrm{C} ; \Delta T_{\mathrm{ad}}$ is the measured adiabatic temperature rise, ${ }^{\circ} \mathrm{C}$; and $C_{0}$ is the initial molality of the sample, $\mathrm{mol} \cdot \mathrm{L}^{-1}$.

Equation (6) can be mathematically integrated to obtain $T M R_{\text {ad, } \mathrm{m}}$, which is the corresponding temperature $T_{\mathrm{D} 24}$ for $24 \mathrm{~h}$. If the effect of $\Phi$ is taken into account, the correction of $\Phi$ needs to be introduced by the following equation:

$$
T M R_{\mathrm{ad} 0}=\frac{T M R_{\mathrm{ad} 0, \mathrm{~m}}}{\Phi} .
$$

The relationship between the measured temperature and $T M R_{\mathrm{ad}, \mathrm{m}}$ under different $\Phi$ for $40 \%$ DCP is shown in Figure 7. Extrapolated from the measured value to the low temperature, the obtained $T_{\mathrm{D} 24}$ is also shown in Figure 7. According to the measured results, equation (7) is used to modify the modified $T_{\mathrm{D} 24}$, as shown in Figure 8.

It can be seen from Figure 7 that under different $\Phi$, the $T_{\mathrm{D} 24}$ of the sample obtained from the test data is different and increases with the increase in $\Phi$. This is because the larger the $\Phi$, the slower the heat release rate of the sample in the initial stage, the lower the temperature rise rate, and the longer the time to reach the maximum temperature rise rate. Figure 8 shows that after the correction of the $T M R_{\mathrm{ad}}$ near the initial decomposition temperature, the relationship between the different $\Phi$ and $T M R_{\mathrm{ad}}$ is relatively consistent and the $T_{\mathrm{D} 24}$ of $40 \%$ DCP obtained by extrapolation of the modified sample sphere is about $87.20^{\circ} \mathrm{C}$. It also shows that after the correction with $\Phi$, the relationship between temperature and corrected $T M R_{\mathrm{ad}}$ is still quite different at a high temperature. However, near the initial decomposition temperature, the results are almost the same. Therefore, it is verified that equation (7) is only applicable to $T M R_{\mathrm{ad}}$ near the modified initial decomposition temperature.

3.6. Checking Analysis with the Fisher Method. As mentioned in Section 3.2, test results are affected by $\Phi$ significantly. A normal Fisher method is to amend the test results to the ideal condition $\Phi=1$, which cannot be realized by the ARC experiment. The experiment data will be corrected to $\Phi=1.64$ in this article and be compared with the measured data.

The corrected equations are as follows:

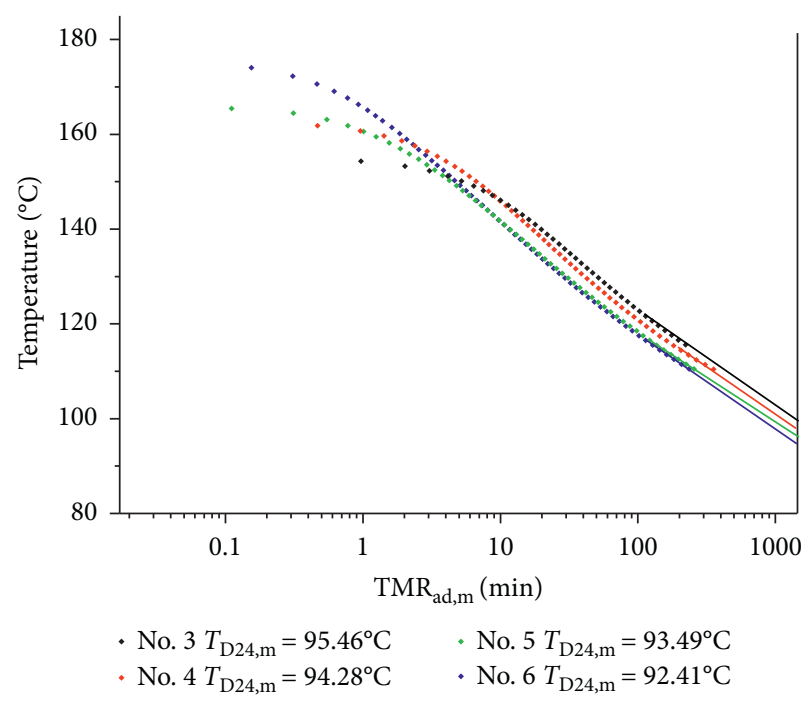

FIGURE 7: The relationship curve between uncorrected solution temperature and $T M R_{\mathrm{ad}, \mathrm{m}}$ for $40 \% \mathrm{DCP}$.

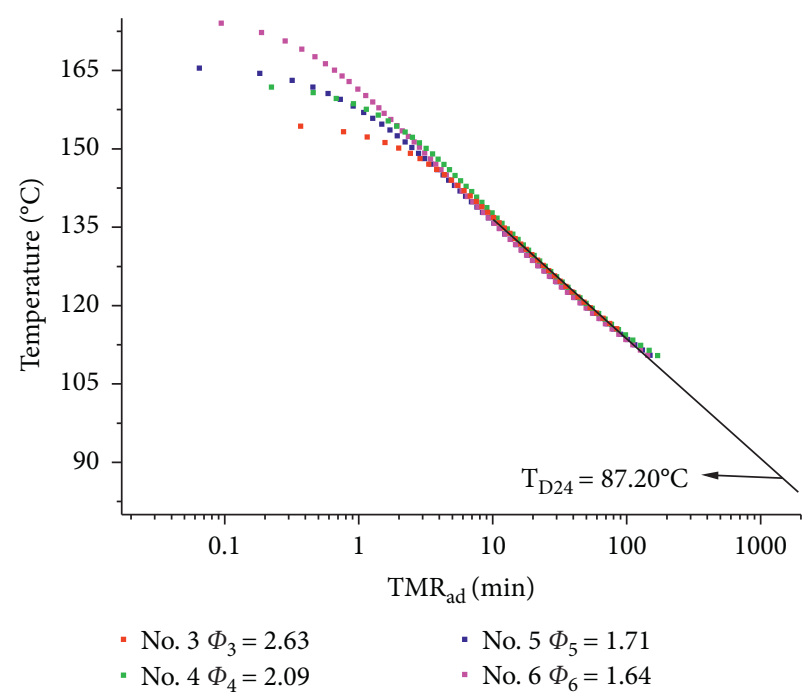

FIgURE 8: The relationship curve between corrected solution temperature and $T M R_{\mathrm{ad}}$ for $40 \% \mathrm{DCP}$.

$$
\begin{aligned}
\frac{1}{T_{\text {on }, \mathrm{a}}} & =\frac{1}{T_{\text {on }, \mathrm{m}}}+\frac{R}{E_{\mathrm{a}}} \ln \frac{\Phi}{\Phi_{1}} \\
T_{\text {ad,a }} & =T_{\text {on, } \mathrm{a}}+\frac{\Phi}{\Phi_{1}}\left(T-T_{\text {on }}\right), \\
\left(\frac{\mathrm{d} T}{\mathrm{~d} t}\right)_{\text {ad,a }} & =\frac{\Phi}{\Phi_{1}}\left(\frac{\mathrm{d} T}{\mathrm{~d} t}\right)_{\mathrm{m}} \exp \left[\frac{E_{\mathrm{a}}}{R}\left(\frac{1}{T_{\text {on }, \mathrm{a}}}-\frac{1}{T_{\text {ad,a }}}\right)\right] .
\end{aligned}
$$

The corrected results are shown in Figure 9 and Table 9. Figure 9 and Table 9 show that when $\Phi$ is close to 1.64, the corrected results such as $(\mathrm{d} T / \mathrm{d} t)-T$ and $T_{\text {on,a }}$ are close to the measured results at $\Phi=1.64$. However, if the test results based on $\Phi$ are far away from the target or predicted condition, the results are very unbelievable. Thus, the weight of the sample has great effect on the result of the ARC test. 


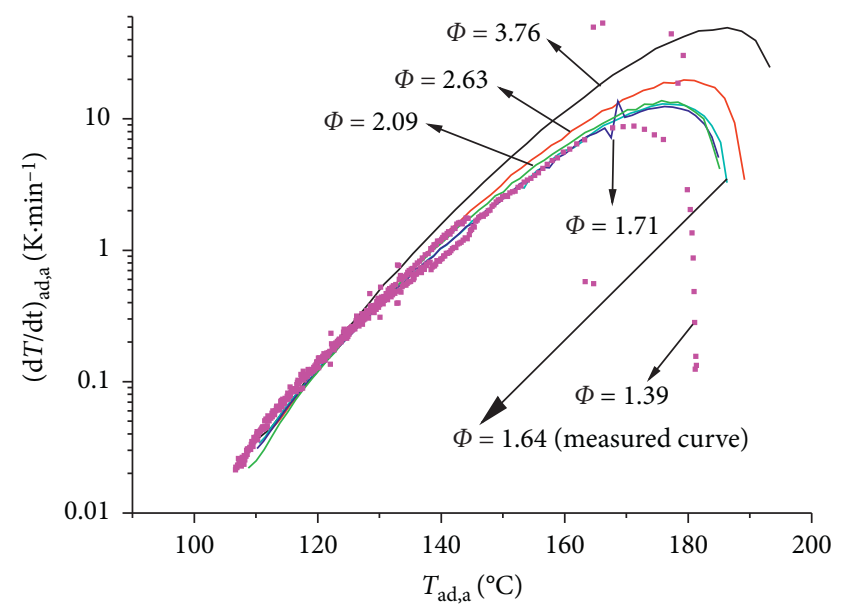

Figure 9: $(\mathrm{d} T / \mathrm{d} t)-T$ corrected to $\Phi_{1}=1.64$ by the Fisher method.

TABle 9: The parameters corrected to $\Phi_{1}=1.64$ by the Fisher method.

\begin{tabular}{lcccccc}
\hline No. & 2 & 3 & 4 & 5 & 6 & 7 \\
\hline$\Phi$ & 3.76 & 2.63 & 2.09 & 1.71 & 1.64 & 1.39 \\
$T_{\text {on,a }}\left({ }^{\circ} \mathrm{C}\right)$ & 110.05 & 112.27 & 108.77 & 110.20 & $110.5^{*}$ & 106.66 \\
$(\mathrm{~d} T / \mathrm{d} t)_{\max , \mathrm{a}}$ & 49.3 & 19.8 & 13.4 & 12.4 & $12.97^{*}$ & 53.6 \\
\hline
\end{tabular}

The values marked with $*$ are measured values.

The study demonstrates that under the condition of safety, $\Phi$ will be close to 1 with the increasing dosage of sample, and the revised ideal adiabatic data will be more reliable.

\section{Conclusions}

40\% DCP with different masses have been studied by using DSC and ARC to obtain its adiabatic decomposition parameters. Then, kinetic analysis is carried out, and the onset temperature and self-heating rate are corrected by the Fisher method. The results indicate that

(1) The calculated $E_{\text {a }}$ value of $40 \%$ DCP is stable under the experimental conditions in the DSC test, and the decomposition followed the one-step reaction mechanism.

(2) The values of $E_{\mathrm{a}}$ and $\ln A$ obtained from the ARC tests show obvious kinetic compensation effect, it means that even under different $\Phi$ conditions, the reaction still follows the same mechanism. The difference from the DSC experiment is that the larger the $\Phi$ value is, the greater the calculated $E_{\mathrm{a}}$ and $A$ values are. It indicates that the value of $\Phi$ will affect the experimental accuracy.

(3) After modification, $\Phi$ has little effect on $T_{\mathrm{D} 24}$ at the initial decomposition temperature, but has greater effect at a high temperature (4) After comparing the results corrected with $\Phi=1.64$ by the Fisher method, it is suggested to perform the test on the condition close to the process condition which is to be predicted, and then it can provide reliable results.

\section{Data Availability}

The data used to support the findings of this study are available from the corresponding author upon request.

\section{Conflicts of Interest}

The authors declare that they have no conflicts of interest.

\section{Acknowledgments}

This work was supported by the National Natural Science Foundation of China (51204099).

\section{References}

[1] S.-J. Shen, S.-H. Wu, J.-H. Chi, C.-C. Lin, J.-J. Horng, and C.-M. Shu, "Simulation of solid thermal explosion and liquid thermal explosion of dicumyl peroxide using calorimetric technique," Simulation Modelling Practice and Theory, vol. 19, no. 4, pp. 1251-1257, 2011.

[2] P. J. Thomas and R. D. Jones, "Extending the J-value framework for safety analysis to include the environmental costs of a large accident," Process Safety and Environmental Protection, vol. 88, no. 5, pp. 297-317, 2010.

[3] A. P. Ding, J. C. Jiang, F. Chen et al., "Thermal decomposition non-isothermal kinetics of dicumyl peroxide in air," Journal of Huaqiao University (Natural Science), vol. 31, no. 2, pp. 183-186, 2010.

[4] M. L. Jiang, J. H. Zhen, and B. Wang, "On the thermal stability and safety of dicumyl peroxide," Journal of Safety and Environment, vol. 14, no. 1, pp. 117-121, 2014.

[5] L. Guo, C. X. Xie, F. Huang et al., "On the thermal safety and stability of dicumyl peroxide," Journal of Safety and Environment, vol. 13, no. 1, pp. 211-214, 2013.

[6] N. Zang and X. M. Qian, "Thermal safety of three kinds of fire work," Chinese Journal of Energetic Materials, vol. 15, no. 2, pp. 172-174, 2007.

[7] H. L. Friedman, "Kinetics of thermal degradation of charforming plastics from thermogravimetry," Application to a Phenolic Plastic, vol. 6, no. 1, pp. 183-195, 1964.

[8] B. Roduit, W. Dermaut, A. Lunghi, P. Folly, B. Berger, and A. Sarbach, "Advanced kinetics-based simulation of time to maximum rate under adiabatic conditions," Journal of Thermal Analysis and Calorimetry, vol. 93, no. 1, pp. 163-173, 2008.

[9] A. Raemy and M. Ottaway, "The use of high pressure dta, heat flow and adiabatic calorimetry to study exothermic reactions," Journal of Thermal Analysis, vol. 37, no. 8, pp. 1965-1971, 1991.

[10] J. K. Wilberforce, The Use of the Accelerating Rate Calorimeter to Determine the SADT of Organic Peroxides, Columbia Scientific Industries, Milton Keynes, UK, 1981.

[11] H. G. Fisher, H. S. Forrest, S. S. Grossel et al., Emergency Relief System Design Using Diers Technology, Columbia Scientific Industries, Milton Keynes, UK, 1993.

[12] Z. Zhang, H. Jiang, and P. Huang, "Study of hydrogen peroxide explosion mechanism and its prevention measures," Journal of Safety \& Environment, vol. 7, no. 4, pp. 108-110, 2007.

[13] H. Liu, L. Gu, P. Zhu, Z. Liu, and B. Zhou, "Evaluation on thermal hazard of ter-butyl hydroperoxide by using accelerating rate calorimeter," Procedia Engineering, vol. 45, no. 3, pp. 574-579, 2012. 
[14] D. I. Townsend and J. C. Tou, "Thermal hazard evaluation by an accelerating rate calorimeter," Thermochimica Acta, vol. 37, no. 1, pp. 1-30, 1980.

[15] R. Z. Hu and Q. Z. Shi, Thermal Analysis Kinetics, Springer, Berlin, Germany, 2th edition, 2008.

[16] D. Dollimore and P. F. Rodgers, "The appearance of a compensation effect in the thermal decomposition of manganese(II) carbonates, prepared in the presence of other metal ions," Thermochimica Acta, vol. 30, no. 1-2, pp. 273-280, 1979. 